\title{
ANh/EP/CP-.93444 CONF-970488--
}

Influence of Environmental Parameters on the

Frictional Behavior of DLC Coatings*

b y

Y. Liu

Louisiana State University

Mechanical Engineering Department

Baton Rouge, LA 70803

A. Erdemir and E. I. Meletis

Energy Technology Division

Argonne National Laboratory

Argonne, IL 60439

\section{RECEIVED \\ JUN 201997 \\ OSTI}

May 1997

\begin{abstract}
The submitted manuscript has been authored by a contractor of the U.S. Government under contract No. W31-109-ENG-38. Accordingly, the U.S. Government retains a nonexclusive, royalty-free license to publish or reproduce the published form of this contribution, or allow others to do so, for U.S. Government purposes.
\end{abstract}

\section{0}

Submitted for presentation at the International Conference on Metallurgical Coatings and Thin Films ICMCTF 97, San Diego, CA, April 21-25, 1997.

*Work supported by the Tribology Program, Office of Transportation Materials, U.S. Department of Energy, under Contract W-31-109-Eng-38.

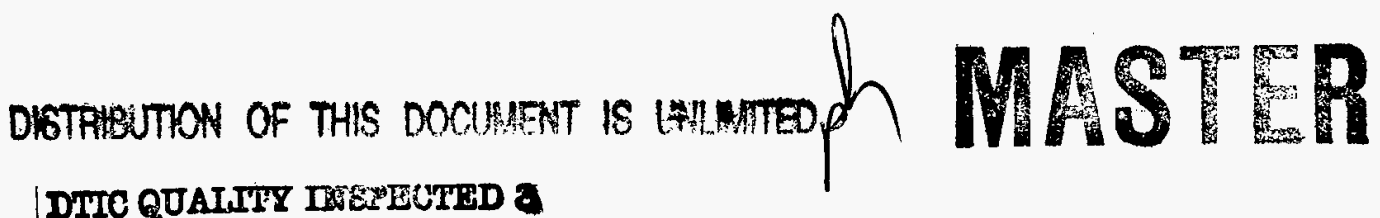




\section{DISCLAIMER}

This report was prepared as an account of work sponsored by an agency of the United States Government. Neither the United States Government nor any agency thereof, nor any of their employees, makes any warranty, express or implied, or assumes any legal liability or responsibility for the accuracy, completeness, or usefulness of any information, apparatus, product, or process disclosed, or represents that its use would not infringe privately owned rights. Reference herein to any specific commercial product, process, or service by trade name, trademark, manufacturer, or otherwise does not necessarily constitute or imply its endorsement, recommendation, or favoring by the United States Government or any agency thereof. The views and opinions of authors expressed herein do not necessarily state or reflect those of the United States Government or any agency thereof. 


\title{
INFLUENCE OF ENVIRONMENTAL PARAMETERS ON THE FRICTIONAL
}

\section{BEHAVIOR OF DLC COATINGS}

\author{
Y. Liu*, A. Erdemir ${ }^{+}$and E.I. Meletis* \\ * Louisiana State University, Mechanical Engineering Department, Baton Rouge, LA 70803. \\ + Argonne National Laboratory, Energy Technology Division, Argonne, II 60439.
}

\begin{abstract}
In our previous studies it was shown that diamond-like carbon (DLC) films possess low friction coefficient $(f)$ and excellent wear resistance. The reduction in $f$ was found to be consistent with a "wear-induced graphitization" mechanism of the DLC structure. A recent study showed that operational parameters (sliding velocity and loading level) influence the tribological behavior of DLC film through control of the kinetics of the graphitization process. The objective of the present siudy was to investigate the influence of environmental parameters (humidity and temperature) on the tribological behavior of DLC film and provide further support to the wearinduced graphitization mechanism. Ion-beam deposition was utilized to deposit DLC on a SiC substrate. Pin-on-disc experiments were conducted by varying humidity $(0 \%, 40 \%$ and $100 \%)$ and temperature $\left(-10^{\circ} \mathrm{C}\right.$ and $\left.25^{\circ} \mathrm{C}\right)$. As-deposited DLC and wear debris was characterized by transmission electron microscopy. It was found that lower humidity increases the graphitization rate more than likely due to the reduction in the effect by the water molecules. A decreased graphitization rate was observed at lower temperature and higher humidity and can be attributed to suppression of temperature rise at hot spots. The present findings are consistent with and further verify the wear-induced graphitization mechanism.
\end{abstract}




\section{INTRODUCTION}

DLC films possess many attractive properties, including high hardness (2000 to 9000 $\mathrm{kg} / \mathrm{mm}^{-2}$ depending on their $s p^{3}$ to $s p^{2}$ ratio and hydrogen content) [1], low friction coefficient $(f$ $\leq 0.15$ in air) [2 3]. Generally, the wear rate of DLC films can be as low as $10^{-15} \mathrm{~m}^{3} / \mathrm{Nm}$. Addition of metals or other elements such as Si into the films can lead to further reduction in wear rate [4]. In addition, DLC coatings possess optical transparency over a wide range of wavelength, good thermal conductivity, and good environmental resistance, for example to aqueous corrosion. Due to these properties, DLC films have elicited considerable interest within high-technology industries, such as magnetic hard disks, ball and rolling bearings, high-precision gears, cutting tools, mechanical seals, etc..

The tribological behavior of DLC films has been previously studied and various theories have been proposed for the wear mechanism [5-8]. Most recently, pin-on-disk experiments conducted on DLC films deposited by methane ion-beam deposition (IBD) techniques showed three distinct friction regimes [9]. Initially a break-in period was observed followed by an intermediate constant friction plateau of a relatively short duration, that preceded a steady-state stage with further reduced values of $f(\leq 0.08)$. Detailed transmission electron microscopy (TEM) investigations revealed that the intermediate friction stage is mainly due to the formation of a transfer layer (occurring by the destabilization of DLC during the break-in stage), whereas the occurrence of steady-state is related to the formation of a graphitized tribolayer. A wear-induced graphitization mechanism was proposed based on the above processes [10].

The operational parameters such as sliding velocity and applied loading level during friction have been found to influence the graphitization process and thus the DLC tribological behavior [11]. Sliding velocity exercises a stronger influence than loading level due to the greater 
effect of contact frequency on the temperature rise at asperities. Development of hot spots facilitates hydrogen release from the DLC structure whereas subsequent shearing under the applied load changes the local structure and completes the wear-induced graphitization process. A predictive equation was developed based on the above two operational parameters to describe the formation rate of the graphitized tribolayer during the wear process [11].

Some investigations of the influence of environmental parameters on tribological behavior of DLC films have been reported [2, 12-15]. The friction coefficient of DLC films against other materials depends on its hydrogen content and the environmental parameters such as humidity and temperature. For hydrogenated DLC films, the friction coefficient varies between 0.1 and 0.2 in humid air and drops to 0.03 in dry nitrogen and can vary between 0.02 and 0.07 in vacuum. It has been found that the low friction coefficient is generally produced by surfaces which are hydrogen terminated, but oxygen or water termination leads to high friction [16]. In the environment of water or oxygen, the friction coefficient of DLC films is usually higher than 0.1 .

In view of the above previous reports, environmental parameters are expected to influence the graphitization process taking place at asperity contacts. For example, higher temperatures are expected to accelerate graphitization kinetics and carbonization (loss of hydrogen) followed by polymerization have been observed in DLC films at elevated temperatures [17]. The motivation behind the present work was to study the effect of environmental parameters (humidity and temperature) on the frictional behavior through influence of the graphitization process in an effort to provide further support to the "environment-induced graphitization" mechanism. 


\section{EXPERIMENTAL PROCEDURES}

DLC films of approximately $2 \mu \mathrm{m}$ thickness, were deposited on $\mathrm{SiC}$ substrate at room temperature by methane IBD using a Kaufmann-type ion source. The deposition was conducted at an accelerating voltage of $750 \mathrm{eV}$ and a current density of approximately $2.5 \mathrm{~mA} / \mathrm{cm}^{2}$. This process produces dense, adherent and low roughness DLC films. The Knoop microhardness of the as-deposited DLC films was about $6000 \mathrm{~kg} / \mathrm{mm}^{2}$. Film characterization studies [18] and the experimental details on the deposition system have been previously reported [9].

Pin-on-disc wear tests were conducted on DLC-coated SiC disc (50 $\mathrm{mm}$ in diameter) using $\mathrm{ZrO}_{2}$ as the pin material (9.55 mm in diameter) under loading levels of $10 \mathrm{~N}$ and different sliding velocities $(0.06 \mathrm{~m} / \mathrm{s}$ and $0.5 \mathrm{~m} / \mathrm{s}$, respectively). The very low sliding velocity was selected in order to reduce the thermal effect of friction on the graphitization process. In addition, during the latter test dry ice $\left(\mathrm{CO}_{2}\right)$ was led to the contacting region by pressurized air producing a $-10^{\circ} \mathrm{C}$ environment. Three humidity levels were selected in order to assess the effect of their intensity on the wear-induced graphitization process. Dry air and water vapor were used to create $0 \%$ and approximately $100 \%$ humidity, respectively.

The variation of friction coefficient during the wear tests was monitored with the aid of a linear variable-displacement transducer and was continuously recorded through the tests. Wear rate calculations for the $\mathrm{ZrO}_{2}$ balls were based on microscopic determination of the diameter (average of measurements in two vertical directions) of the wear scars. The wear volume of DLC film was estimated from the traces of surface profiles across the wear tracks (average of three measurements) obtained by using a surface profilometer.

Analytical TEM with electron diffraction was carried out to study the microstructures of as-deposited DLC film and of the wear debris collected from wear track after the testing. Fine 
particles of as-deposited DLC film and wear debris wear scratched from the disc using a sharp blade and transferred onto copper grids for TEM examination.

\section{RESULTS AND DISCUSSION}

The TEM observations showed that the as-deposited DLC film has mainly a featureless microstructure (Figure 1). Electron diffraction patterns from as-deposited DLC film showed the presence of diffuse rings indicative of the amorphous nature of the films (Figure 1). Two diffuse rings were mainly observed with $d$-spacing of approximately $2.1 \AA$ and $1.2 \AA$ consistent with previous studies $[9,18]$. The measured $d$-spacing of the two rings for the as-deposited DLC film is suggesting the presence of a short-ranged diamond-like structure considering that (111) and (220) are the strongest diffraction for crystal diamond and corresponding to $d=2.06 \AA$ and 1.26 $\AA$, respectively.

Table 1 summarizes the testing parameters and experimental results for the $\mathrm{ZrO}_{2} / \mathrm{DLC}$ coated $\mathrm{SiC}$ pair. More specifically, the related parameters include the initial Hertzian contact pressure $\left(\sigma_{H}\right)$, the initial and steady-state coefficients of friction $\left(f_{\text {in }}\right.$ and $f_{s s}$, respectively), the sliding distance to reach steady-state $(S)$ and the wear rate of the ball $\left(W_{B}\right)$ and disc $\left(W_{D}\right)$ material. It is evident that environmental humidity and temperature have significant effect on the tribological behavior of DLC film. Figure 2 presents the variation of the friction coefficient with sliding distance of DLC-coated SiC substrate for the various experimental conditions.

\subsection{Influence of humidity on the tribological behavior of DLC film}

The influence of humidity on the tribological behavior can be deduced by comparing tests

1, 2 and 3. Test 1 was conducted at normal laboratory environment (humidity $\sim 40 \%$ ) which 
represents ordinary application environment for DLC films. This test produced low wear of pin and disc, $0.66 \times 10^{-9} \mathrm{~mm}^{3} \mathrm{~m}^{-1} \mathrm{~N}^{-1}$ and $0.8 \times 10^{-7} \mathrm{~mm}^{3} \mathrm{~m}^{-1} \mathrm{~N}^{-1}$, respectively. The coefficient of friction had a relatively higher initial value and a very low value at steady-state $\left(f_{s s}=0.075\right)$. This tribological behavior is in agreement with our previous studies $[3,9]$.

Figure 3(a) presents the morphology and microstructure of debris collected from the wear track after test 1 . The TEM observations revealed that the debris microstructure was distinctly different from that of as-deposited DLC. Electron diffraction analysis showed that graphite was present in the wear debris, which confirmed the graphitization process occurring during friction. Electron diffraction pattern analysis from the wear debris showed mainly the $(0002)_{\mathrm{GR}} s p^{2}$ graphite reflection $(d \approx 3.4 \AA)$, Figure $3(b)$. Dark field analysis showed that the graphite particles had a size of about $3-4 \mathrm{~nm}$ and exhibited a formation pattern, more than likely coinciding with the sliding direction, Figure 3 (c). Similar observations regarding the microstructure of the graphitized layer were made in our early study [11] and show that after nucleation, there is limited growth in the graphite particles suggesting that they develop at localized hot spots. This suggests that when a thin graphitized tribolayer develops, the friction is reduced and no further transformation occurs in the DLC film. These microstructural changes in the DLC film during friction confirm the graphitization and low friction in the steady-state stage of tests 1 and 2.

The observed low friction coefficient in test 1 can be attributed to the formation of graphitized tribolayer between the pin and disc materials, and as a result, the low shear strength between hexagonal planes in graphite structure. Under this condition, after the steady-state stage is reached, the wear process can be envisioned as a low-rate continuous consumption and generation of graphitized tribofilm. The extensive sliding distance $(40 \mathrm{~km})$ required before reaching low friction steady-state indicates a very low graphitization rate under this humidity 
level. This behavior can be also represented by a low value of graphitization rate, $R=0.13$, (reciprocal of the time required to reach the low friction steady-state stage).

Test 2 was performed in dry air ( $0 \%$ humidity). The experimental results showed very low $f$ values at steady-state $\left(f_{s s}=0.02\right)$, low values of $S(1.97 \mathrm{~km})$ and wear rate of pin and DLC film all consistent with enhanced graphitization occurring during friction. The very low wear volume of DLC film and the corresponding high calculated graphitization rate, $R(2.53$, almost 20 times that of test 1) are equitable with very short sliding distance $(1.97 \mathrm{~km})$ to reach steady-state. The low wear rates of pin and DLC-coated disc can very reasonably be attributed to the low friction coefficient in large portion of the friction process.

In the high humidity environment (test $3,100 \%$ humidity), the friction process can be described by constant friction coefficient. The relatively high values of $W_{D}{ }^{\prime}$ and $W_{P}$ ' are attributed to the direct contact between pin material and the hard DLC film rather than between the pin and a soft tribolayer in the wear track. Also, the continuous high friction coefficient $\left(f_{\text {in }} \approx f_{s s}=0.10\right)$ suggests that no significant graphitization occurred during friction under such a high humidity environment.

Through analyzing tests 1,2 and 3, it can be seen that humidity of environment exercises a significant influence on the graphitization process of DLC film. Humidity can affect the friction process by changing the composition at the pin/disc contact interface. Hydrogen atoms have been recognized to play an important role in contact bonding between DLC film and its counterface [16]. Due to their low electrochemical strength, a hydrogen atom usually produces a weak bonding with other materials. This can explain the fact that hydrogen attached to DLC surface possesses a lower friction coefficient, compared with that in other environments [16].

Hydrogen attached on as-deposited DLC surface can originate from the environment or from the interior of the film since hydrogen atoms are thought to be released from the DLC 
structure during the break-in stage and probably diffuse towards the surface of DLC film. It is obvious that the absorbed water molecules by free DLC surface may reduce the absorption of hydrogen atoms or block the diffusion of hydrogen atoms onto the free surface. In addition, the water vapor from high humidity environment can condense on the contact area and may dissolve the loose tribolayer formed during friction. This can result in the continuous direct contact between pin and disc materials, and thus high friction coefficient and wear rate, as found in test 3.

Furthermore, according to the wear-induced graphitization mechanism [10], a condensed water layer at asperity contacts can have a cooling effect on small "hot spots" and thus reduce significantly friction-induced thermal effects. Consequently, high enough flash temperatures may not be attained and the graphitization kinetics are expected to be suppressed.

In an extremely low humidity environment $(0 \%$, test 2$)$, the observed low friction coefficient, low wear rates of both pin and DLC film and high graphitization rate show that a dry environment promotes the graphitization process. The present results show that increasing the humidity level, the coverage of asperity contacts by water molecules decelerates the graphitization process. In very high humidity environment $(100 \%$, test 3$)$, no graphitization was observed and relatively high values of $f$ are maintained.

Previous studies have reported on methods to reduce the humidity sensitivity of DLC films by reactive sputtering small amounts of metals into the DLC film structure. It has been found that the films with about $15 \%$ metallic additions have less humidity degradation [19]. Additions of silicon to DLC film can also improve the performance of DLC with low friction coefficients $(<0.1)$ in both humid and dry conditions. It was thought that at high humidity, silica sol was formed on the DLC surface which can reduce friction coefficients [19]. 


\subsection{Influence of temperature on the tribological behavior of DLC film}

The significance of temperature on the tribological behavior can be found by comparing tests 1 and 4 . It is interesting to note that at $-10^{\circ} \mathrm{C}$, the DLC film was worn out after a short sliding distance $(3.5 \mathrm{~km})$ and was followed by a sudden increase in the friction coefficient, Figure

2. This phenomenon resulted in very high wear rates of pin and disc materials $\left(60.3 \times 10^{-9} \mathrm{~mm}^{3} \mathrm{~m}^{-}\right.$ ${ }^{1} \mathrm{~N}^{-1}$ and $4.89 \times 10^{-7} \mathrm{~mm}^{3} \mathrm{~m}^{-1} \mathrm{~N}^{-1}$, respectively), compared with the corresponding data for test 1.

The influence of environment temperature on the tribological behavior of DLC film is consistent with and further validates the proposed wear mechanism [10]. It was thought that the flash temperature produced by friction on local "hot spots" at the contact region is responsible for the release of hydrogen atoms causing relaxation in the hard DLC structure. This relaxation permits shearing of the DLC structure under the applied load completing the structure transformation. The "hot spots" are expected to be cooled down due to the heat loss by conduction and convection during the time interval between two subsequent contacts. The escaping of hydrogen atoms from the DLC structure is actually based on the heat accumulation in large number of contacts. The low temperature of the environment can accelerate the heat transfer process by increasing conduction and convection between local "hot spots" and environment. The continuous heat loss by conduction and convection from friction-induced "hot spots" restricts the release of hydrogen atoms from the DLC structure and the subsequent formation of low shear strength tribolayer. The direct contact between the hard DLC film and pin for long distance during friction produced high wear rate of pin and disc materials, as indicated by test 4 . 


\section{CONCLUSIONS}

The present investigation showed that the low friction coefficient of DLC film (steadystate stage) was due to wear-induced graphitization. Environmental humidity and temperature were both found to affect the tribological behavior of DLC film. Increasing the level of environmental humidity was found to decelerate the graghitization process. This can be attributed to the condensed water layer on the contact interface that may prevent generation of high flash temperatures, block the absorption and diffusion of hydrogen atoms, and affect integrity of newly formed tribolayer. At low environment temperature no graphitization was observed since higher thermal conduction and convection rate can cool down the "hot spots" rapidly and suppress nucleation of graphite on "hot spots". The present observations are fully consistent with and provide further support to the wear-induced graphitization mechanism.

\section{ACKNOWLEDGMENT}

Funding for this work was provided by the Louisiana Educational Support Fund under contract LEQSF (94-96)-RD-B07 and the U. S. Department of Energy. 


\section{REFERENCES}

[1]. A. Grill, V. Patel and B. S. Meyerson, in Y. Yzeng, M. Yoshikawa and A. Feldman (eds.), Applications of Diamond Films and Related Materials, Elsevier, 1991, p. 683.

[2]. A. Erdemir, M. Switala, R. Wei and P. Wilbur, Surf. Coat. Technol., 50 (1991) 17.

[3]. E. I. Meletis, A. Erdemir and G. R. Fenske, Surf. Coat. Technol., 73 (1995) 39.

[4]. H. Dimigen and C. P. Klages, Surf. Coat. Technol., 49 (1991) 543.

[5]. A. Imamura, T. Tsukamoto, K. Shibuki and S. Takatsu, Surf. Coat. Technol., 36 (1988) 161.

[6]. K. Miyoshi, R. L. Wu and A. Garscadden, Surf. Coat. Technol., 54-55 (1992) 428.

[7]. S. D. Gorpinchenko, S. M. Klotsman, E. V. Kuzmina, S. A. Plotnikov and I. S. Trachtenberg, Surf. Coat. Technol., 47 (1991) 201

[8]. A. Erdemir, F. A. Nichols, X. Z. Pan, R. Wei and P. Wilbur, Diamond Relat. Mater., 3 (1993) 119.

[9]. Y. Liu, A. Erdemir and E. I. Meletis, Surf. Coat. Technol., 82 (1996) 48-56.

[10]. Y. Liu and E. I. Meletis, J. of Mater. Sci., (1997, in print).

[11]. Y. Liu, A. Erdemir and E. I. Meletis, Surf. Coat. Technol., (1997, in print).

[12]. J. Franks, K. Enke and A. Richardt, Met. Mater., November (1990) 695.

[13]. A. M. Jones, C. T. Bedell, G. Dearnaley, C. Johnston and J. M. Owens, Diamond Relat. Mater., 1 (1992) 416.

[14]. T. Hioki, Y. Itoh, S. Hibi and J. Kawamoto, Surf. Coat. Technol., 46 (1991) 233.

[15]. R. S. Bhattachaya, R. L. Wa and C. S. Yust, Nucl. Instrum. Methods B, 59/60 (1991) 1383.

[16]. D. Paulmier, H. Zaidi, H. Nery, T. Le Huo and T. Matthia, Surf. Coat. Technol., 62 (1993) 570. 
[17]. J. Robertson, Adv. Phys., 35 (1986) 317.

[18]. V. Palshin, S. Ves, S. Logothetidis and E. I. Meletis, Thin Solid Films, 270 (1995) 165.

[19]. H. Dimigen, H. Hubsch and R. Memming, Appl. Phys. Lett., 50 (1987) 1056. 
Figure Captions

Figure 1. Transmission electron micrograph showing typical microstructure of as-deposited DLC film on SiC substrate. The insert is the corresponding electron diffraction pattern.

Figure 2. Variation of friction coefficient with sliding distance of DLC-coated SiC substrate.

Figure 3. (a) Bright field transmission electron micrograph showing typical morphology of wear debris, (b) the corresponding electron diffraction pattern and (c) dark field image (obtained by using part of the central graphitic ring) showing morphology of wearinduced graphite particles. 
Table 1. Summary of Friction Tests of $\mathrm{ZrO}_{2}$ on DLC-Coated SiC Substrate.

\begin{tabular}{|cccccccccccc|}
\hline $\begin{array}{c}\text { Test } \\
\text { No }\end{array}$ & $\begin{array}{c}\text { Velocity } \\
\text { v }(\mathrm{m} / \mathrm{s})\end{array}$ & $\begin{array}{c}\text { Load } \\
(\mathrm{N})\end{array}$ & $\begin{array}{c}\mathrm{T} \\
\left({ }^{\circ} \mathrm{C}\right)\end{array}$ & $\begin{array}{c}\text { Humidity } \\
(\%)\end{array}$ & $\begin{array}{c}\sigma_{H} \\
(\mathrm{MPa})\end{array}$ & $f_{\text {in }}$ & $f_{s s}$ & $\begin{array}{c}S \\
(\mathrm{~km})\end{array}$ & $\begin{array}{c}W_{B}^{\prime} \\
\left(\mathrm{x} 10^{-9} \mathrm{~mm}^{3} \mathrm{~m}^{-1} \mathrm{~N}^{-1}\right)\end{array}$ & $\begin{array}{c}W_{D}^{\prime} \\
\left(\times 10^{-7} \mathrm{~mm}^{3} \mathrm{~m}^{-1} \mathrm{~N}^{-1}\right)\end{array}$ & $\begin{array}{c}R \\
\left(\times 10^{-4} \mathrm{~s}^{-1}\right)\end{array}$ \\
\hline 1 & 0.5 & 10 & 25 & 40 & 851 & 0.16 & 0.075 & 40 & 0.66 & 0.80 & 0.13 \\
2 & 0.5 & 10 & 25 & 0 & 851 & 0.07 & 0.02 & 1.97 & 0.68 & 0.63 & 2.53 \\
3 & 0.5 & 10 & 25 & 100 & 851 & 0.10 & 0.10 & $\mathrm{NG}$ & 1.12 & 1.05 & - \\
4 & 0.06 & 10 & -10 & 40 & 851 & 0.15 & 0.30 & $\mathrm{NG}$ & 60.3 & $4.89 /(3.5 \mathrm{~km})^{*}$ & - \\
\hline
\end{tabular}

$\sigma_{H}=$ initial Hertzian stress, $f_{i n}$ and $f_{s s}=$ initial and steady-state coefficient of friction, respectively, $S=$ sliding distance before reaching steady-state stage, $W_{B}{ }^{\prime}$ and $W_{D}{ }^{\prime}=$ wear rate of ball and disc, respectively, $R=$ graphitization rate (inverse of time required to reach graphitization), $N G=$ no graphitization occurred;

* The number in parenthesis indicates the distance at which the film was worn out. 


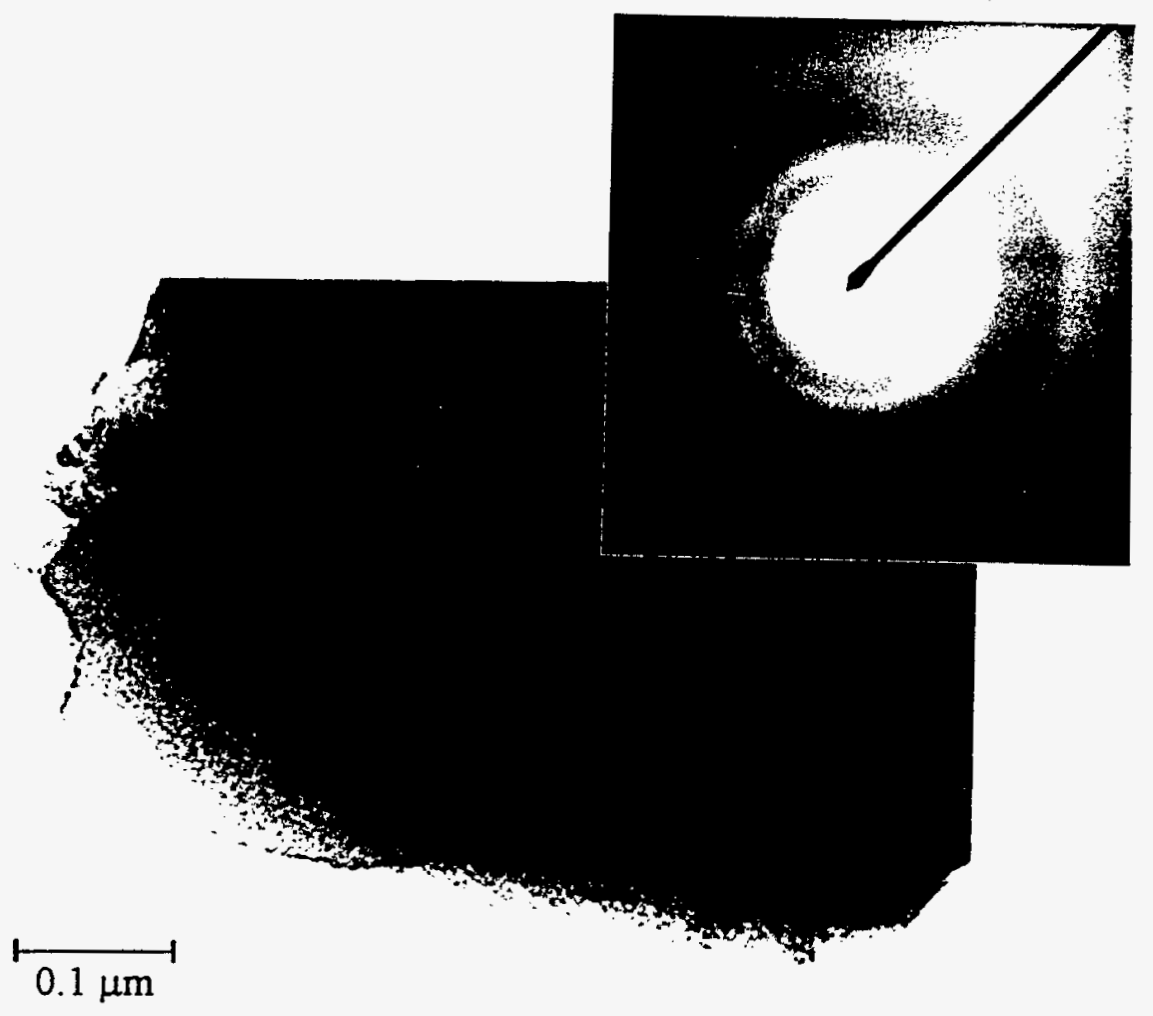

Figure 1. Transmission electron micrograph showing typical microstructure of asdeposited DLC film on SiC substrate. The insert is the corresponding electron diffraction pattern. 


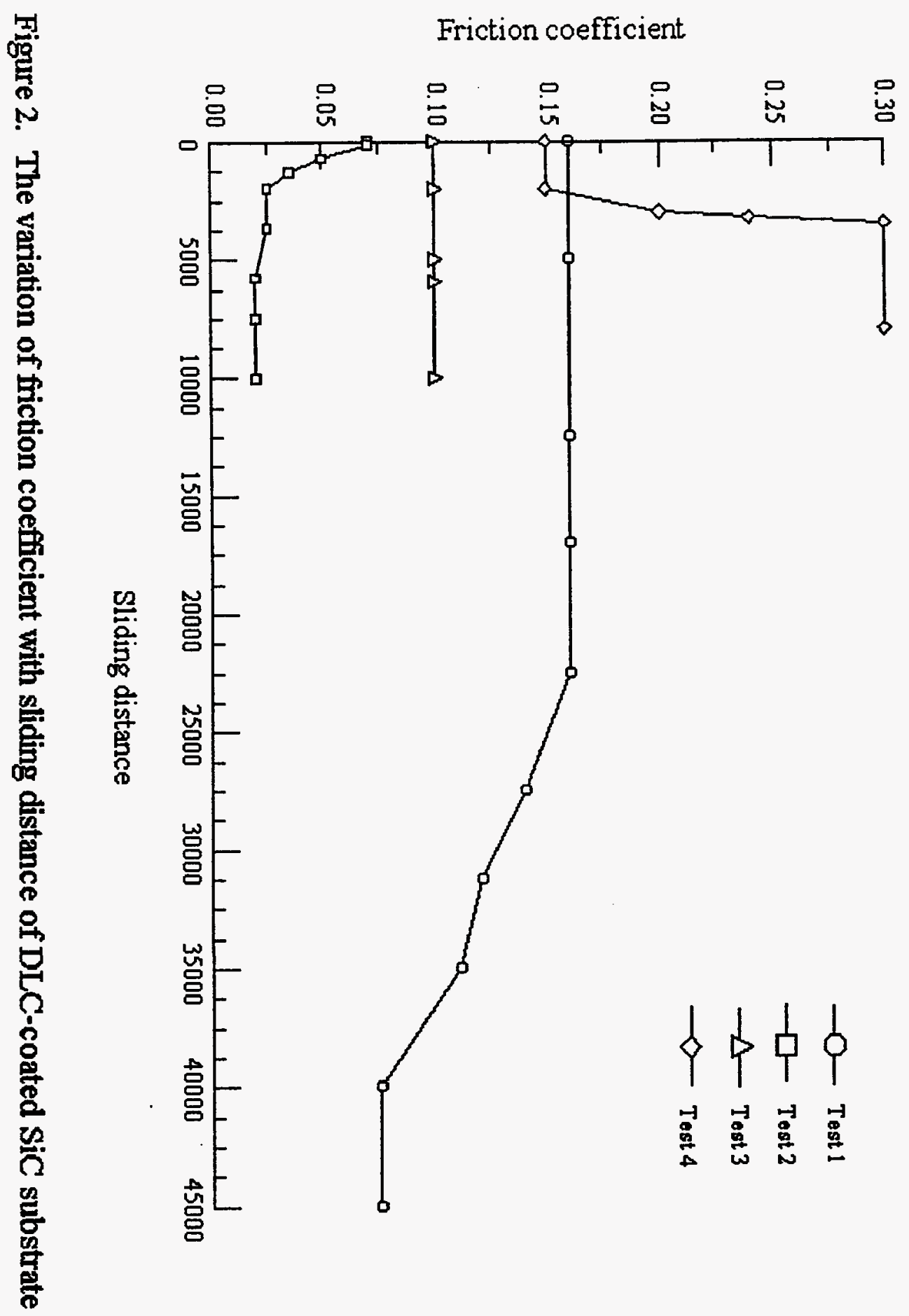




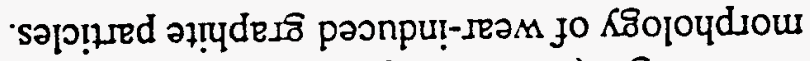

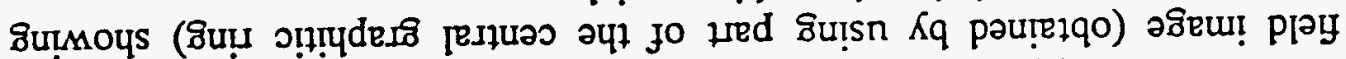

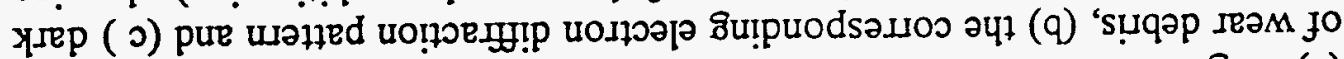

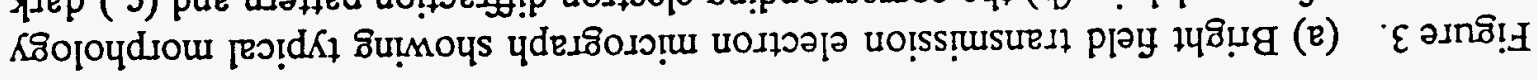
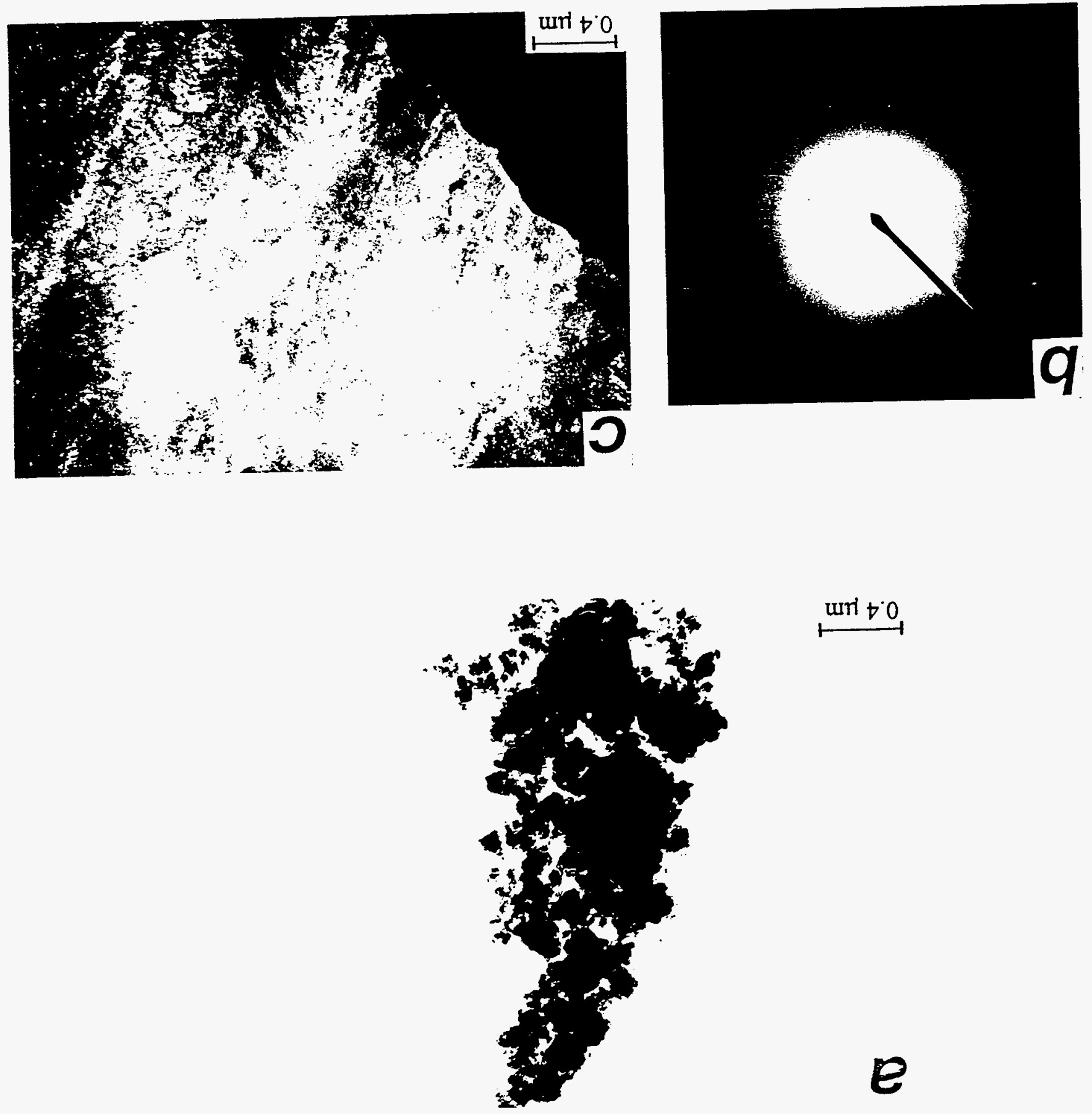

$\stackrel{\text { urnt } \rightarrow 0}{\longleftarrow}$ 
M97053383

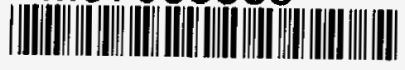

Report Number (14)ANL/EP/CP- 93444
CONF-970488--

subl. Date (11) 199705

sponsor Code (18)
JC Category (19)

DOE 